\title{
Is Gabriel Garcia Marquez a Malayali?
}

\begin{abstract}
Translations have greatly influenced, enriched and transformed Malayalam literature. Yet one is often baffled by the lack of adequate reviews and studies of these translations in Kerala where translation has occupied a key position in the literary polysystem. Even the reviews that do appear display a propensity to treat the translated texts not as translations but as works 'natural' to Malayalam, thus negating their foreignness and making them prey to too easy an appropriation into the oeuvre of Malayalam literature. Such reviews and readings in turn both promote and breed annexationist translations and also sanctify imitations, adaptations and rewritings often without due acknowledgements of the original. This paper argues that in a culture too ready to invest the foreign language text with domestic significance, the process of domesticating the text continues from the act of translation to that of reading and reviewing. This could be the reason why the reviews too are generally seen to be inscribed with domestic intelligibilities and ideologies, treating the translated work rather as a domestic inscription than as one bearing the function of inter-cultural communication.
\end{abstract}

Meena T. Pillai

Malayalam, which belongs to the Dravidian family of languages, is the mother tongue of over thirty million people, most of whom live in Kerala but many of whom are also dispersed across the globe. As Paniker says,

Like the speakers, the language also has been receptive to influences from abroad and tolerant of elements added from outside. Malayalam literature too reflects this spirit of accommodation and has over the centuries developed a tradition, which even while rooted in the locality, is truly 
universal in taste. It is remarkably free from provincialisms and parochial prejudices that have bedevilled the literature of certain other areas. To its basic Dravidian stock have been added elements borrowed or adopted from nonDravidian literatures such as Sanskrit, Arabic, French, Portuguese and English. The earliest of these associations was inevitably with Tamil. Sanskrit, however, accounts for the largest of the 'foreign influences' followed closely in recent times by English. This broad based cosmopolitanism has indeed become a distinctive feature of Malayalam literature. (Paniker 1998: 9)

Malayalam literature has been greatly influenced and transformed by translations and innumerable authors and great books have all found a space for themselves in Malayalam through translation. The first conscious literary endeavour in Malayalam and probably its first epic poem, Ramacharitam believed to have been penned in the twelfth century A.D. can be called a translation and is a retelling of the Yuddha Kanda of Valmiki Ramayana. Probably the first translation of the Bhagavad Gita into a modern Indian language was into Malayalam by Madhava Panikkar, one of the Niranam poets in the fifteenth century. In the same century, Niranathu Rama Panikkar translated the Ramayanam and Kannassa Bharatam. During this time, Sankara Pannikkar made a remarkable condensation of Mahabharatam and called it Bharatamala.

In the sixteenth century Thunchathu Ezhuthachan, considered the father of Malayalam poetry, translated the Ramayanam and the Mahabharatam. His Adhyatma Ramayanam and Srimahabharatam used the 'Killippattu' form where he devised a new narrative technique of using the bird or 'Kili' as the narrator of the poem. Ezhuthachan's bird can thus be treated as a metaphor of the process of translation itself. However, scholars like Ayyappa Paniker have pointed out that Ezhuthachan was not a mere translator but that '.. in fact he follows the earlier Kerala writers in freely elaborating or considering the original as he thinks proper. The celebration of this freedom gained in poetic creation is what enlivens and ennobles the hymns interspersed in his works' (Paniker 1998: 30). 
It would be worthwhile to examine now the function attributed to translation in that age by these ancient scholars. Cheeraman, the translator of the Ramayanam in the twelfth century expounds his aim in writing Ramacharitam. He says: 'Uzhiyil cheriyavarkariyumaruna cheyvan' meaning, enlighten the common folk of this world. The Niranam poets also had the specific purpose of Dravidianization of Aryan mythology and philosophy and together 'they constitute the strong bulwark of the Bhakti movement which enabled the Malayalies to withstand and resist the onslaught of foreign cultures' (Paniker 1998: 23).

\section{As Devy says,}

These translations were made without any inhibition, and they rarely maintained a word-for-word, linefor-line discipline. The categories useful for the study of these translations are not 'the TL and the SL' or 'the mother tongue and the other tongue'. The poets/writers attempting vernacular rendering of Sanskrit texts treated both the languages as their 'own' languages. They had a sense of possession in respect of the Sanskrit heritage. But in translating the Sanskrit texts they sought to liberate the scriptures from the monopoly of a restricted class of people. Hence these translations became a means of re-organising the entire societies (Devy 1993: 149).

One cannot but agree with Devy here, and assert that no theory with an exclusively linguistic orientation can be adequate to understand the magnitude of translation activity in Kerala at that time.

In the modern era, the first play in Malayalam was a translation of Kalidasa's Abhijnana Sakuntalam by Kerala Varma Valiya Koyitampuran in 1882. The first attempt at writing a novel was again a translation titled Ghataka Vadham (The Slayer's Slain). O. Chandu Menon's Indulekha (1889) believed to be the first perfect novel in Malayalam was also the result of an attempt to translate the English novel genre into Malayalam. Even the first book printed in Kerala in 
1821 was a translation titled Cheru Paithangalude Upakarartham Englishil Ninnum Paribhasha Peduthiya Kathakal (Stories Translated from English for the Benefit of Little Children). The Bible translations under the leadership of Herman Gundert and Benjamin Bailey also played a great role in shaping Malayalam prose.

It is also significant to note that very early in the history of Malayalam language there started a plethora of translations from other Indian languages into Malayalam. The first translation of a Tamil text was into Malayalam in 1595 A.D. This was the prose translation of Thirukural by Aikaramatho Panikkar. There were numerous translations of the Gitanjali into Malayalam. Most of the great poets and writers of Malayalam were also able translators. Kumaranasan's translation of Ramayana for children, Changampuzha's and G. Sankara Kurup's translations of Omar Khayyam's Rubayyat, Sankara Kurup's translation of Gitanjali in addition to the pioneering works already mentioned merit special attention.

To say that translated litrerature has always maintained a key position in the literary polysystem in Malayalam would thus not be an exaggeration. My point in detailing this aspect of Malayalam language and literature is to explicate how, for the relatively small and less dominant linguistic group of Malayalies, translation has always been an activity of inclusion and assimilation as much as resistance and subversion. Almost all the early translations in Malayalam strove to promote native registers, dialects, discourses and style, in the process uniformly struggling to erase the foreignness of the source text. Translation has thus been part of Malayalam literature's attempt to crystallize and strengthen itself by incorporating the experiments, strengths and resources of other literatures. One can safely surmise that in the context of Kerala, translation can be 'readily seen as investing the foreign language text with domestic significance....because the translator negotiates the linguistic and cultural differences of the foreign text by reducing them and supplying another set of differences, basically domestic, drawn from the receiving language and culture to enable the foreign to be received there' (Venuti 2000: 468). 
My argument in this paper is that this process of domestication which begins with the very choice of texts to be translated to the act of translation per se, continues in the process of reading and culminates in the review or the absence of it. Thus, the review too in such a context is often seen to be inscribed with domestic intelligibilities and ideologies. This could be one of the reasons why translation reviewing has never been given much importance in Malayalam.

A reviewer of any translation should first seek to answer why a particular work was chosen for translation at a particular point of time. This attempt to correlate the principles of selection to the literary systems of the source and target culture would provide valuable insights into the position and role of the translated work within a given culture and language. Instead most reviews in Malayalam treat these works not as translations but as works 'natural' to Malayalam, thus negating their foreignness and making them prey to too easy an appropriation into the oeuvre of Malayalam literature. Such reviews and readings in turn promote annexationist translations and sanctify imitations, adaptations and paraphrasing often without acknowledging the original. Reviews are often seen to treat the translated work as a domestic inscription rather than one that bears the function of intercultural communication.

Here I would like to cite the example of the renowned critic Kuttikrishna Marar's review of the Malayalam translation of Premchand's Godan by Divakaran Potti (Marar 1957: 92-97). The whole review is a vitriolic attack on Premchand whose ideologies and aesthetic ideals Marar could never see eye to eye. The review is a battle between Premchand, the social reformist writer and Marar, an unstinting champion of the values of classical criticism. The review is nowhere a review of the translation of Godan but a battle of two clashing ideologies taking place in the Kerala society of the fifties. Marar's review makes possible only a domesticated understanding of Premchand and his rating of Premchand is inversely proportional to the degree of subversiveness that Premchand induces in the domestic. Marar remains immune to the question of whether the translated 
Godanam communicates the basic elements of the narrative form of the original or to the analyzing of shifts in translation or to the level of transmission of the invariants or even to the argument of whether invariance is at all possible in a translation from Hindi to Malayalam.

It is easy for the translator, reader and reviewer of a minority linguistic community to deflect from the foreignness of the 'Translated Text' and focus instead on the degree of its conformity or opposition to dominant domestic ideologies and interests inscribed in it. Such agendas, strategies and interests are often determined by the function that is attributed to translation in a particular culture. In the case of a reformist work like Godan that had received wide readership all over India, the translation could become the site for a reviewer like Marar to challenge or contest the upcoming trends of an era of change. Thus Marar uses Godanam as a context to foster a community of readers who would oppose the progressive socialist, reformist trends in literature in Kerala. For this, he adopts a universalist stance, rejecting the specificity of the translated work and focusing instead on its broad and general aspects. What Marar in fact attempts to do is to position Godan in the novel tradition of Malayalam and attack Premchand for not conforming to the norms and conventions of this tradition. Thus, what Marar finds in the translation discourse of Godanam is so familiar a subversion of his own critical conventions that he seems to mistake Premchand for one of his Malayali adversaries of the Progressive Writers Forum.

Such a lack of perception on the part of reviewers stems, I feel, not from the lack of knowledge of the nature and scope of translation or its norms. It stems from a willing suspension of such norms in the larger interest of a socio-cultural function attributed to translation by a cultural community. Translation does not take place in a vacuum and it is the target culture's 'needs' and objectives that largely govern the translational activity taking place in that culture. Thus when the transnational behaviour and responses taking place within a culture start manifesting certain regularities, one can safely surmise that the norms that particular culture attributes to translation 
have manoeuvred different shifts of validity and reached a fairly stable axis of normativity. Translations in Malayalam are largely acceptability oriented and adhere to target culture norms. For example, the large number of Russian and Marxist literature which found their way into Malayalam, is beyond doubt due to the popularity of leftist ideology in the state. Thus the translation policy regarding the 'choice' of what to translate seems to predominate over other translation norms like operational norms and textual-linguistic norms that govern the relationship between the ST and TT and the selection of linguistic material to formulate the TT respectively.

Any translation, which according to Berman ought to be 'a trial of the foreign,' (Berman 2000: 284) often becomes its negation, acclimation and naturalization. Often the most individual essence of the ST is radically repressed and this is where one feels the need for proper reviewing and reflection on the ethical aim of the translating act of receiving the foreign as foreign. A review that does not respect the linguistic and cultural differences of the ST, in fact, promotes bad translation ethics and helps in creating a tribe of ethnocentric translators. The absence of proper reviewing and studies of translation could also lead to the neglect of translation norms which further pave the way for weak, entropic, lacklustre translations.

As a land that has witnessed since ancient times scores of foreign influences and interactions from Chinese and Arab travellers to the Portuguese, Dutch, French and English Colonial interventions, Kerala has remained remarkably open to the complex heterogeneity of the historical and cultural discourses thus generated. In the twentieth century, one can see two things which probably brought in a definite agenda to translation activity in Kerala and connect the pre-modern with the modern. The first is of course a compulsive need to be part of a pan-Indian consciousness in the backdrop of the independence struggle and the awakening of a spirit of nationalism. The second is the anxiety of a small socio-linguistic group to negotiate the boundaries between the local and the international during its engagement with the language of modernity. These contradictory impulses signal the 
rise of translation from other Indian languages like Bengali and Hindi on the one hand and from foreign languages on the other. Nevertheless, this rise in translation did not create a corresponding theoretical discussion of Translation Studies or create the need for a realistic historiography of translation criticism. Kerala and its people, having been exposed to multiple languages and cultures, have a 'translating consciousness' as Devy (1992) would call it. But this consciousness has been made so familiar and humdrum that it has not been thought worthwhile to invest any effort in discussing the aesthetics of translation or its theorization. Thus, translation, which should have brought in a new strength to Malayalam literature, falls short of this function by remaining constricted by an overpowering native culture and unhoned by sharp critical tools. Therefore, the failure to capture the vital and transitory energy of a cross-cultural enterprise in any systematic framework also leads to the lack of evolving an appropriate methodology for studying translation. This leaves the average reader seriously crippled by neither knowing what to expect of a translation nor having any critical tools to judge it. Though any critical analysis of Malayalam literature cannot overrule the great role of translation in shaping its literary tradition, it is indeed a shocking revelation that there have been no studies of the history of literary translation or its critical postulates, nor does it find any serious mention in any of the prominent texts on literary criticism in Malayalam. Thus there is an imperative need for a reorganized historical perspective of literary criticism in Kerala with a more punctilious scrutiny of the process of assimilation of the 'foreign' and 'other Indian' traditions and texts into Malayalam.

Even as we acknowledge the fact that this little strip of a land ensconced between the Arabian Sea and the Western Ghats experienced waves of alien influx on its soil from time immemorial one is reminded of Devy's statement,

'Colonial experience releases several conflicting tendencies in the colonized society. It creates simultaneously a revivalistic romanticism and a hardheaded political 
pragmatism. This simultaneous release of several conflicting tendencies results in a strange, superficial cultural dynamics. A colonized culture becomes violently progressive and militantly retrogressive, and in consequence tends to remain static. In order to understand this cultural immobilization, an appropriate historiography is of prime importance' (Devy 1992: 4).

This violent progression and militant retrogression are evident in the profusion of translations in Malayalam as also in the apathy to review them. Translation is a voracious activity in Malayalam but this untrammelled appetite coupled with the lack in efficacy of the intellectual tools of Malayalam literary criticism to review or assess the process and act of translation leads to a state of literary dyspepsia. Though it can be said that translation in Kerala has a history of nearly eight hundred years, the continuing practice has not given rise to any significant and original translation theory. Such theorization would have helped bring in some critical rigour in the analyses of translation praxis.

Without acknowledging the original Spanish language or culture from which it was translated into English and not revealing whether it is a translation of the Spanish original or the English translation by Gregory Rabassa, translations such as Ekanthathayude Nuru Varshangal in fact situate themselves in an ambivalent space between two languages and cultures. No review of the translation has raised the question of what the direct source text of the Malayalam translation is, whether it is the Spanish Cien Anos de Soledad by Marquez or the English One Hundred Years of Solitude translated by Rabassa.

If the Malayalam translator has used the English translation, is he equipped to translate the inscriptions of the original Spanish text or has he been forced to adopt the English version as 'the transparent vehicle of universal truth, thus encouraging a linguistic chauvinism, even a cultural nationalism'? (Venuti 1998: 92). Thus, what is called 
for urgently is proper reviewing of translated texts so that the issue of translation is not side stepped in the process of celebrating the taming of the foreign by over-valorizing the native language and culture.

The translation of One Hundred Years of Solitude carries two studies of the original which again fail to anchor the text in its historical and cultural context, resulting in a translation which appears freefloating and unhinged from the specificities of history to occupy a universal realm which transcends linguistic and cultural differences.

The grave handicap of studies and reviews not recognizing a text as translated leads to a seriously limited and provincial understanding of texts. Reviews of translation in Malayalam thus need a double focus and should aim to look at the foreign text and culture as well as the translating text and culture. Such reviews could then generate translation discourses and methodologies that would help view culture not as a monolithic concept but as a space where heterogeneous histories and languages commingle and also seek to look at the differential levels of power and privilege under which such activities take place. Such reviews could help reveal how 'different forms of reception construct the significance of the foreign text, and also which of these forms are dominant or marginalized in the domestic culture at any historical moment' (Venuti 1998: 94). Reviews, which can unravel the varying degrees of subordination, which most translations inflict on the source, would thus help reveal the hierarchy of domestic values that produce appropriative movements in the translation encounter and asses the cultural and political significance of such attempts at domestication.

The influence of Chinese, Portugese, Dutch and British cultures in Kerala and the immigration of Keralites in large numbers to all parts of the world in the twentieth century raise certain fundamental questions about identity. Even as Malayalis within Kerala raise a rallying cry against globalization and the hegemony of multinational economics, can one really close one's eyes to the flow of global capital in the State or the exodus of Malayalis moving across 
every permeable national boundary in the world? The term Malayali has itself thus become the epitome of 'hybridity,' of 'in-between-ness' that postcolonial critics like Bhabha celebrate.

Within the discourse of hybridity that so permeates the Malayali psyche, it is possible to argue that translation is also an act of subversion, which seeks to topple the originality of the original. Thus translation could also be a devouring, a ritualistic eating to assimilate the vitality of the source text in the process of rejuvenating the target language and literature. Such vampire translations which have thrived in Kerala reject the concepts of 'imitation' and 'influence' and come to represent today a typically postcolonial attitude towards cultural dialogues with dominant ideologies, as vampirism, whereby the translator sucks out the blood of the source text to strengthen the target text, as transfusion of blood that endows the receiver with new life, can all be seen as radical metaphors that spring from post-modernist post-colonial translation theory' (Bassnett 1993: 155). But I would argue that such translations were in currency in Kerala even before the knowledge of post-colonial theory and is a powerful statement of instances of native resistances to colonial power hierarchy, be it Sanskrit or English which privilege a particular text as 'original' and relegate the 'other' as 'translation'.

It is western literary and critical theories that have 'suffered' most at the hands of such 'vampire translations.' In Malayalam, literary and philosophical theories ranging from structuralism, cultural materialism, feminism, post-structuralism and deconstruction and a host of other ideas formulated by eminent philosophers and critics from the west have found their way into Malayalam indiscriminately and over-zealously with no proper introduction or acknowledgement, through translations, adaptations and paraphrasing.

It is interesting to note in this context how John Bunyan's famous allegory The Pilgrim's Progress was translated into Malayalam by no less than Herman Gundert, the most important name among colonial missionaries who worked in Kerala in the nineteenth century 
and became famous for his Malayalam-English dictionary. In Gundert's Malayalam translation, the hero Christian, as he traverses through the valley of blood, bones, ashes and dead men, comes across 'Rakshasas' he had not met in the English version. They are 'Vigrahasuras' who are attended by the likes of Rama, Krishna and Narayana. A little further on, Christian meets 'Mohammed Rakshasa' the arch enemy of the 'Vigrahasuras' who has a sword in one hand and the Quran in the other. Even as this translation leaves one appalled, it speaks volumes of the necessity of making translation visible as an intensely political activity, and in the light of the lack of any concerted critique or efforts to study it, forces a reassessment of the cultural and pedagogical practices that might rely solely on such translated texts. However, even as I argue that translation in Kerala is an intensely political activity, often without the Malayali being conscious of it being so, there is still the need to theorize its political and cultural implications and study the different methodologies that could effectively be used to make it truly interdisciplinary and intercultural. It is high time critics and reviewers gave serious attention to translation policies and strategies and attempt to mend their conceptual inadequacies and evolve a concrete methodology to tap its subversive potential.

\section{References}

Bassnett, Susan (1993) Comparative Literature: A Critical Introduction, Oxford: Blackwell.

Berman, Antoine (2000) "Translation and the Trials of the Foreign" in Lawrence Venuti (ed.) The Translation Studies Reader, London: Routledge, 276-289.

Devy, G. N. (1992) After Amnesia: Tradition and Change in Indian Literary Criticism, Hyderabad: Orient Longman. 
- (1993) In Another Tongue: Essays on Indian Literature in English, Madras: Macmillan.

Marar, Kuttikrishna (1957) Danthagopura, Kozhikode: Marar Sahithya Prakasam.

Paniker, K. Ayyappa (1998) A short History of Malayalam Literature, Thiruvananthapuram : Department of Public Relations.

Venuti, Lawrence (1998) The Scandals of Translation: Towards an Ethics of Difference, London: Routledge.

— (2000) "Translation, Community, Utopia" in Lawrence Venuti (ed.) The Translation Studies Reader, London: Routledge, 482-502. 